\title{
A POSSIBILITY TO ESTIMATE THE IMPACT OF THE METALLURGICAL POLLUTANT NOISE SOURCES ON THE SURROUNDING ECOLOGICAL SYSTEMS
}

\author{
1,2Dan CONSTANTINESCU, ${ }^{2,3}$ Adriana Beatrice CARLAN \\ ${ }^{1}$ University Politehnica of Bucharest, Romania, EU \\ ${ }^{2}$ SNSIM, Cluj Napoca, Romania, EU \\ ${ }^{3}$ IMNR, Bucharest, Romania, EU \\ dconstantinescu@ecomet.pub.ro, danco@ines.ro
}

https://doi.org/10.37904/metal.2021.4071

\begin{abstract}
The work analyzes the influence of some pollutant elements due to metallurgical plants (defined as "metallurgical systems") on the environment. The noise is an important pollutant factor. It can produce dangerous effects on the peoples as well as on the environment, buildings, animals and vegetation. The impact of pollutant metallurgical sources on the ecological systems is a complex issue. The complexity is due to the fact that the pollution is not a local problem, but it has also influences, through the most dynamic vectors on the environment, on very large zones (defined as ecozones). These effects can be observed at a regional and global level. The work takes into account the ecozones surrounding a metallurgical plant, their complexity and the possible interference as well. The study uses real data offered by some metallurgical plants, relating to pollutant agents and to their spreading zones. The final scope of the study is to establish the influence of these factors on the ecosystems where the metallurgical factory lay out and to offer a model that could make easier taking some decisions relating to the improvement of the utilized technologies.

As the sources and severity of noise pollution continue to grow, there is a need for new approaches to reduce exposure.
\end{abstract}

Keywords: Metallurgicalsystems, noise, pollution, efects, environment

\section{INTRODUCTION}

Each year 138 millions tons of pollutant materials are evacuated in the environment including important quantities of ferrous and nonferrous metals, ferrous oxides, gazes, slag etc. In the same time we have not to ignore the efect of the noises. The main causes the metallurgical pollutant are the intensive exploitation of industrial installations, technological causes, absence or low efficiency of ecological filters. Unfortunately, the industrial development, having as priority the increase of the production, has caused new phenomena of industrial pollution. From this, metallurgy has a special importance.[2]

In Figure1 is presented the structure of a

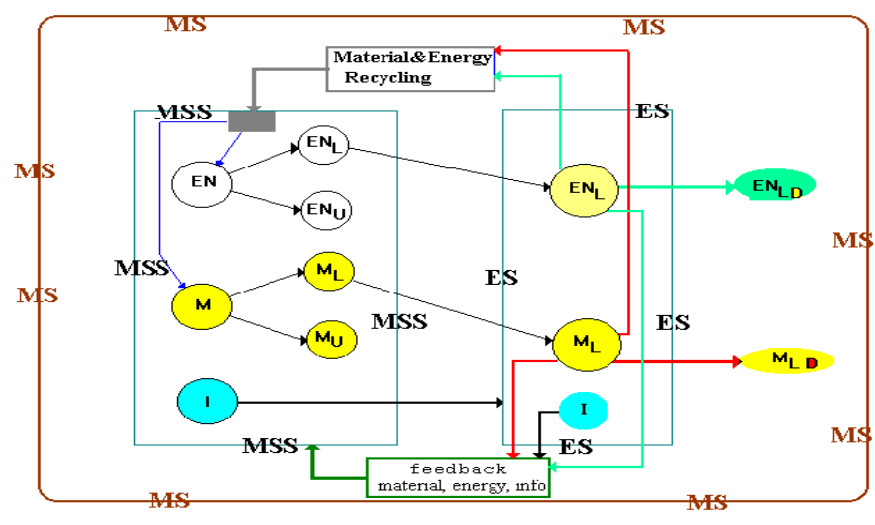
metallurgic system in connection with an ecological system [1].

Figure 1 The structure of a metallurgical system (MS); MSS: metallurgical subsystem [EN: energy; M: material; I: information; L: lost; u: used; LD: lost definitively]; ES: environmental subsystem 
The potential pollutant products, including the noise polutant, represent second degree of pollution, as they do not affect the pollutant potential of the metallurgic subsystem (MS).

\section{METHODOLOGY AND ORGANIZATION OF THE RESEARCHES}

The study methodology is focused on two directions: the establishing of the indicators to analyze the pollution due to a metallurgical system and the estimation of the impact of the noise pollutants on surrounding ecosystem, including the effect on the peoples, animals, and buildings.

For example, in order to analyze a continuous casting line as system (CAROBIL=casting and rolling of the billets) it is necessary to consider it as composed by three systems: S1, S2 and S3 (Figure 2).

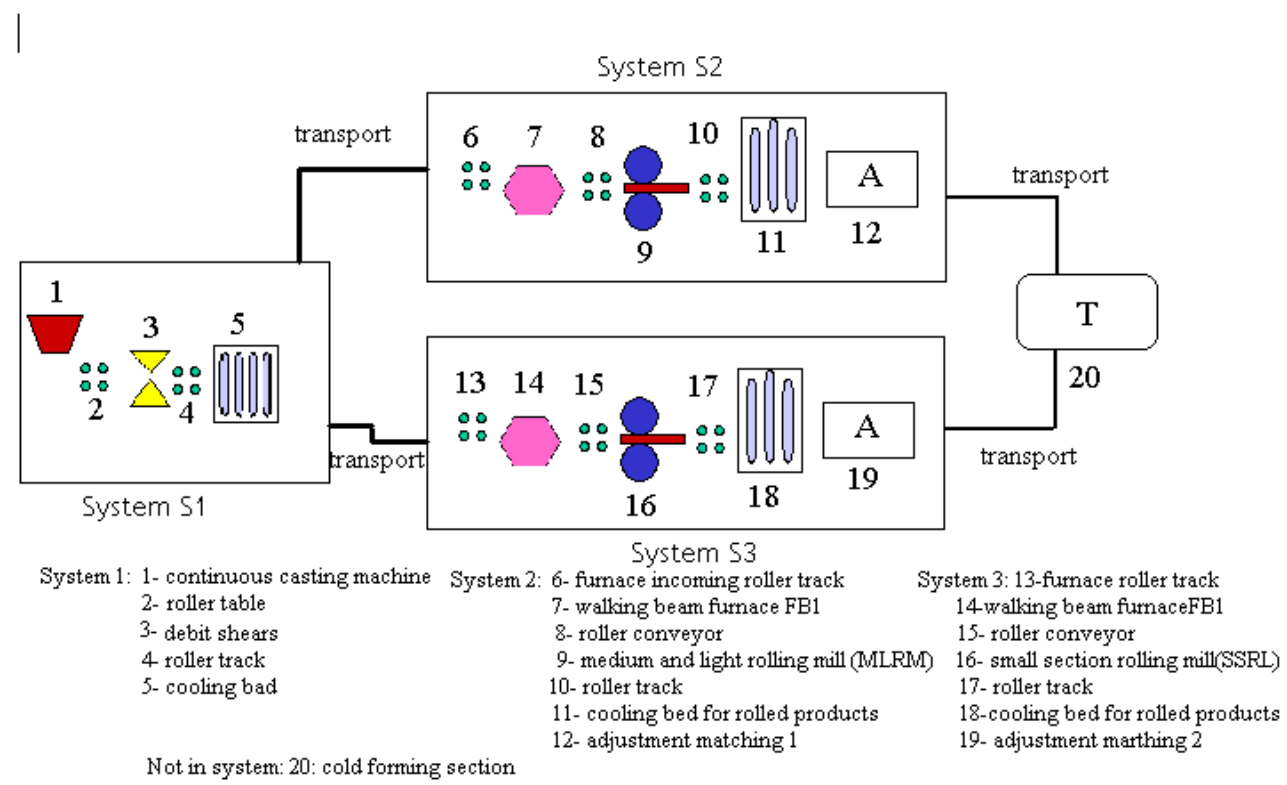

Figure 2 CAROBIL technologicalsystem

Figure 3 represents the metallurgical system named "CAROBIL", composed by three secondary systems, subsystems and components.

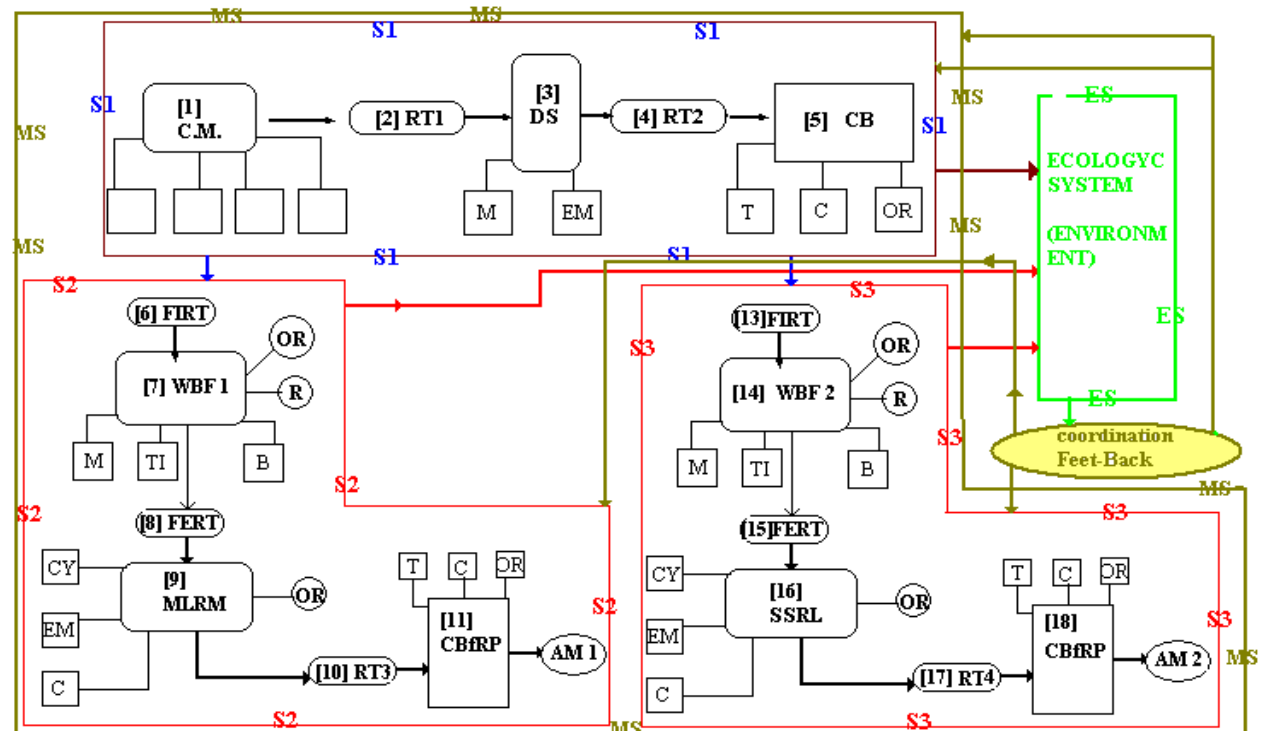

Figure3 CAROBIL - systems, subsystems, components and connectionwiththe environment system 
In Figure 3, there are the following notations: MS: Metallurgical system (CAROBIL); ES: Ecological system; the numbers and notations correspond to Figure 2; notation for components are: M- mechanic component; EM- electric motor; T- transport component; C- cooling; OR- metallic oxide recuperation; TI- thermal isolation; B- burners; R- heat recuperation; CY- cylinder of rolling mill; WBF- walking beam furnace; FIRT- furnace incoming roller track; FERT- furnace exit roller track; CBfRP- cooling bet for rolled products.

To analyze the system, it is necessary to have in view that each subsystem is composed by "components". It can be energetic, material or informational connections between components or directly between a component and a subsystem.

\section{RELATION REGARDING THE ACOUSTIC VIBRATION}

The noise can be introduced as acoustical vibration without very clear defined components, unpleasant sound. The velocity [3] of the sound can be established with the relations:

- $\quad$ in the gazes (air):

$v=\sqrt{\frac{1}{K \cdot \rho}}=\sqrt{\frac{\gamma \cdot \rho_{0}}{\rho}}$

where: $\quad \mathrm{K}$ - adiabatic compressive, $\mathrm{m} \cdot \mathrm{kg}^{-1} \cdot \mathrm{s}^{2}$

$\rho-$ density of the environment temperature, $\mathrm{kg} \cdot \mathrm{m}^{-3}$

$\rho_{0}-$ density at the normal temperature, $\mathrm{kg} \cdot \mathrm{m}^{-3}$

$\gamma=\frac{c_{p}}{c_{v}}-$ the ratio between the mass thermal capacity

Bell: no dimensional unit used for the comparison of the values of the acoustic powers. $(1 \mathrm{~dB}=0.1$ Bell)

Table 1 Noise intensity in some thermal aggregate

\begin{tabular}{|c|c|}
\hline Thermal aggregate & Noise intensity \\
\hline Steel making furnace & $100 \mathrm{~dB}$ \\
\hline AC electric arc furnace & $120 \mathrm{db}$ \\
\hline Plasma furnace for steel & $92 \mathrm{~dB}$ \\
\hline DC arc furnace & $92 \mathrm{~dB}$ \\
\hline Crucible induction furnace & $110 \mathrm{~dB}$ \\
\hline Acidic converters & $110 \mathrm{~dB}$ \\
\hline
\end{tabular}

In the case of solid bodies, the noise velocity is [3]:

- $\quad v_{\text {long }}=\sqrt{\frac{E(1-v)}{\rho\left(1-\nu-2 \gamma^{2}\right)}}$

is the longitudinal speed

- $\quad v_{\text {trans }}=\sqrt{\frac{E}{\rho(1+v)}=\sqrt{\frac{G}{\rho}}}$

is the transversal speed.

The sound velocity, experimental, for some media of noise transfer is presented in table 2 and figure 4 . 


\section{EUROPEAN COMMISSION AND THE PROTECTION AGAIN THE NOISE}

In the EU, more than 100 million citizens are affected by noise levels above $55 \mathrm{~dB}$ (a threshold at which negative effects on human health can be observed) [4]. Road traffic is the most prominent source for such noise, followed by noise from railways, airports and industry.

Table 2 Noise velocity in some materials media [3]

\begin{tabular}{|c|c|c|}
\hline Media (material) & Temperature, ${ }^{\circ} \mathbf{C}$ & Noise velocity, $\mathbf{m} / \mathbf{s}$ \\
\hline Air & 500 & 558 \\
\hline Air & 20 & 344 \\
\hline Air & 0 & 331 \\
\hline Air & -20 & 319 \\
\hline $\mathrm{CO}_{2}$ & 100 & 297 \\
\hline $\mathrm{CO}_{2}$ & 18 & 265 \\
\hline Water & 25 & 1197 \\
\hline Sea water & 15 & 1498 \\
\hline Steel & depending on the category & $5050-6100$ \\
\hline Aluminum & depending on the category & $5240-6400$ \\
\hline Copper & depending on the category & $3580-4606$ \\
\hline
\end{tabular}

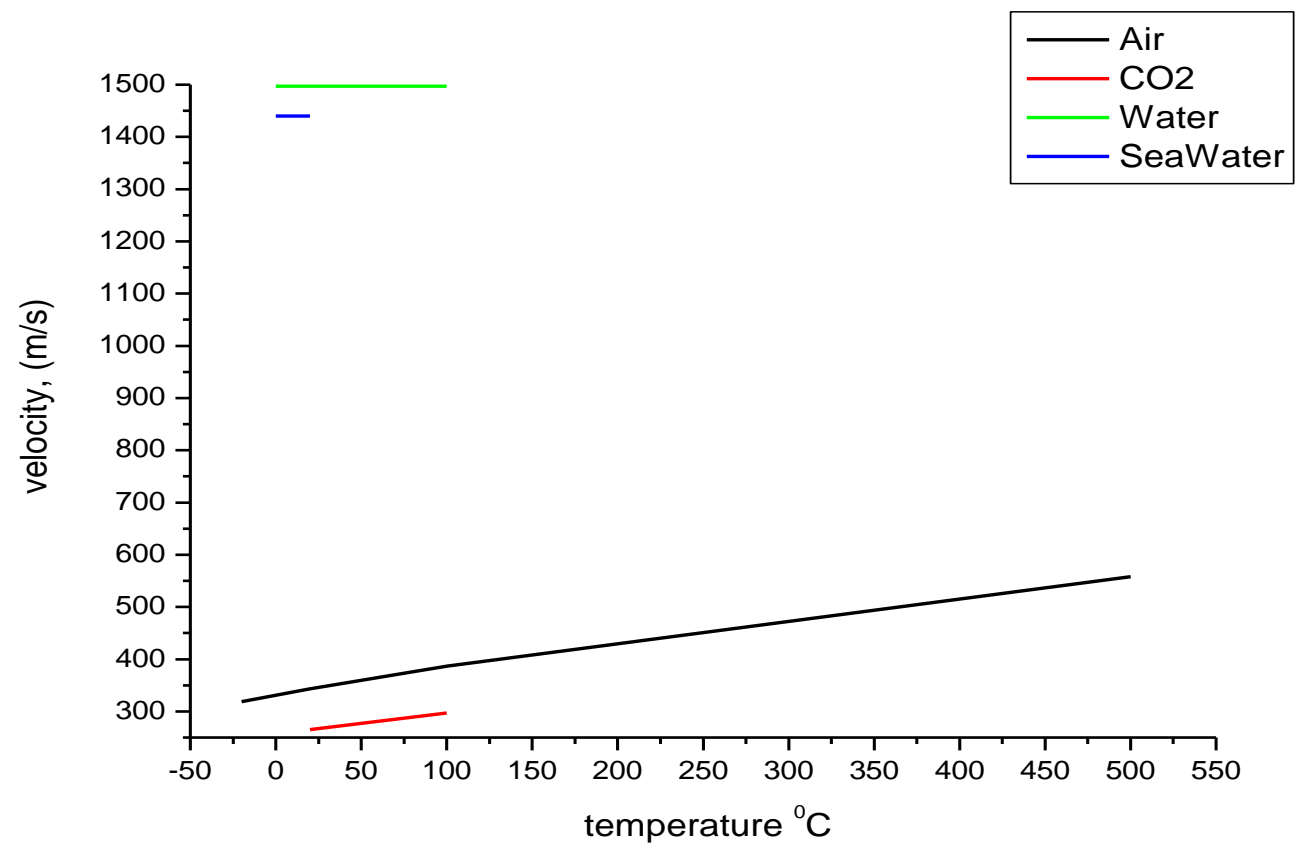

Figure 4 Velocity of the noise in the air, carbon dioxide and water, m/s (established: D. Constantinescu)

This means that around 14 million citizens are annoyed by environmental noise and around 6 million sleep disturbed [3]. This is associated with an estimated 70000 hospital admissions and 16000 premature deaths per year(Source: European Commission (2017) [4].

In Figure 5, there are presented the distribution of the noise sources and the population it affects. 


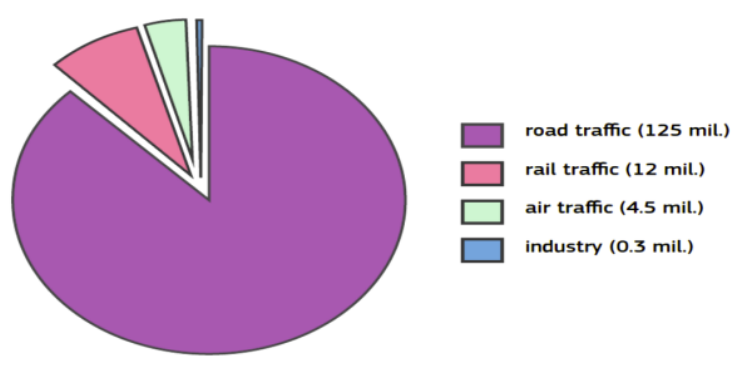

Figure 5 Distribution of European population exposed to sound levels above $55 \mathrm{~dB}$ by noise sources (Source: adapted from Blokland and Peeters (2016) and based on noise mapping data from EEA (2014), extrapolated to 100\% coverage over Europe.

Figure 6 represents the severity of the effects of the noise on the people

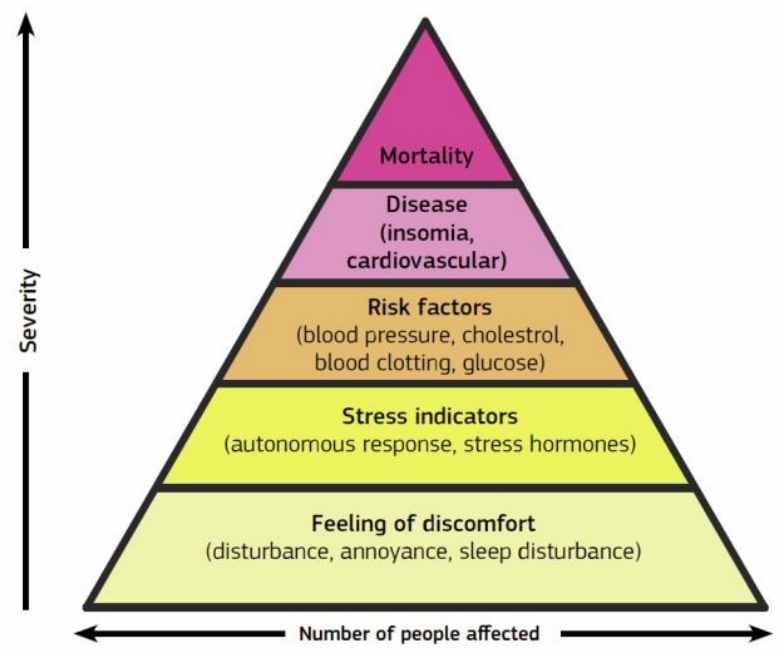

Figure 6 The pyramid of nois induced health effects. (Sourse: EU Comission, April 2017, issue 17; adapted from Babish W, The noise/stress concept, risk assement and research meeds)

\section{PARTICULARITIES REGARDING THE INDUSTRIAL NOISE}

Although transportation is the major contributor to environmental noise pollution, there are many other, more localized sources of environmental noise, such as industrial sites, metallurgical sites (Figure 7), construction sites, landfills and even wind turbines.

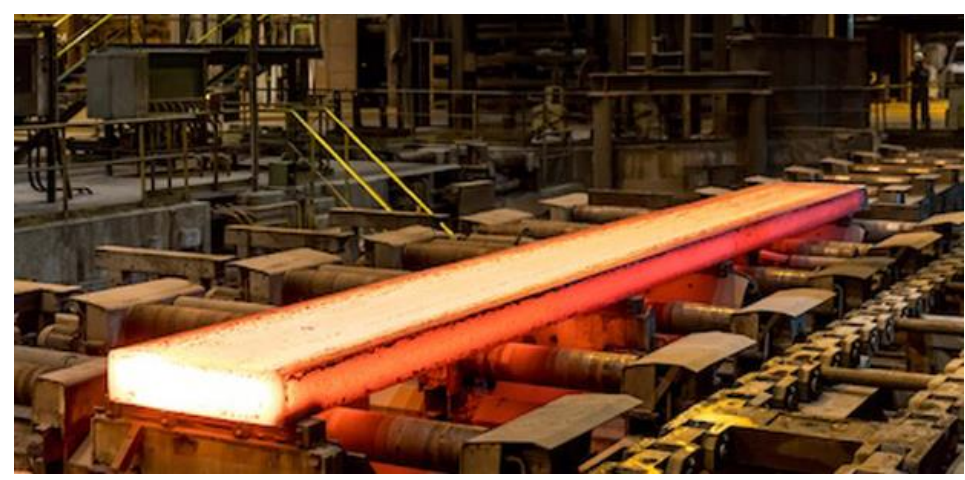

Figure 7 Salzgitter AG adds low CO2 steel grades to its product range (Source: Carsten Brand/Salzgitter Industrial-type noise can cause particular annoyance due to its intermittent and low-frequency nature (Murphy and King, 2014). 
Mechanical noises, which can produce a sensation of vibration, are considered especially annoying by people. There are also more specific noise mitigation approaches for industry, including shock mounting equipment [5] and damping to reduce vibrations, acrylic glass barriers and machine guards. A more pro-active approach to noise abatement is to design machinery with reduced sound emissions. In the EU, the Outdoor Noise Directive (2000/14/EC) imposes noise limits for 22 different types of equipment and requires noise marking for a total of 57 equipment types. "Lden" is an indicator of the overall noise level during a day used to describe the discomfort associated with noise exposure. It is calculated from the indicators "Lday", "Levening", "Lnight", averaged sound levels over the periods $6 \mathrm{am}-6 \mathrm{pm}, 6 \mathrm{pm}-10 \mathrm{pm}$ and $10 \mathrm{pm}-6 \mathrm{pm}$. In addition, a weighting of 5 $\mathrm{dB}(\mathrm{A})$ is applied in the evening period and $10 \mathrm{~dB}(\mathrm{~A})$ at night, to take into account the fact that we are more sensitive to noise during these periods.

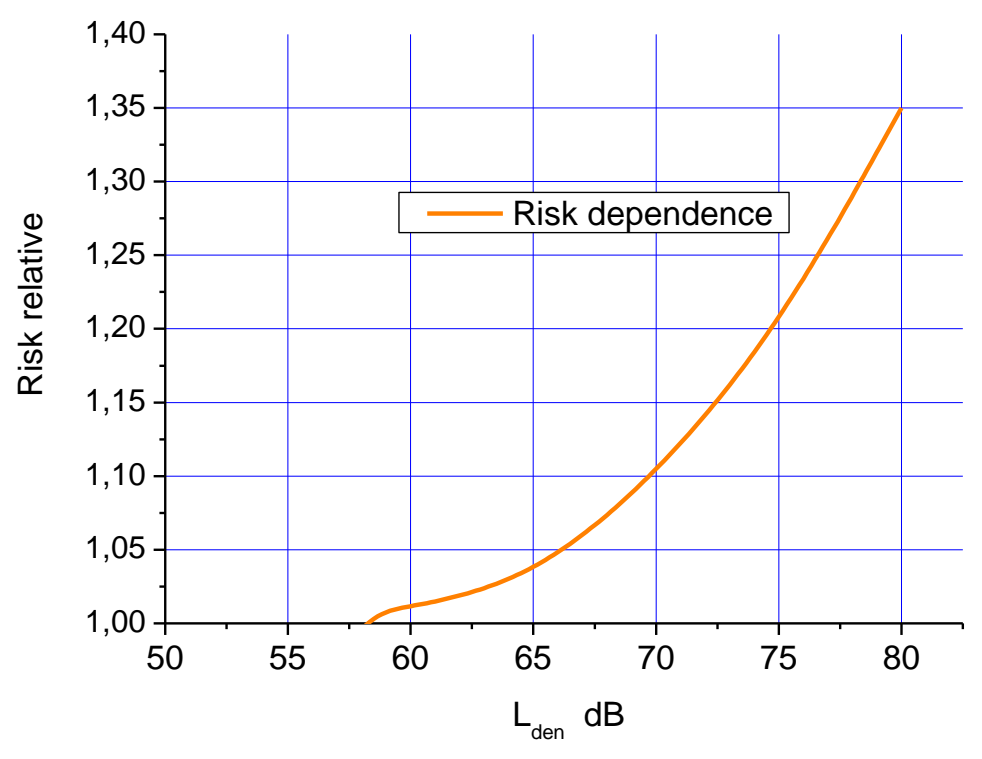

Figure 8 Relation between the noise and the relative risk of incidences and the myocardial infarcts (representation in Origin, after "Lettre d'information de Bruit", nr.20, September 2015)

\section{CONCLUSIONS}

Metallurgy is one of the most complex industrial branch, but also one of the most pollutants. Gazes (including "green house" gases effect), dust, solid and liquid pollutant, but also noise, are some of the most important examples.

Noise is one of the most pervasive and complex environmental pollutants, driven by a combination of factors including urbanisation, economic growth, expanding transport networks and increasing industrial output (European Environment Agency, 2014). As recognition of its public health implications grew at the end of the 20th Century, dedicated European legislation was developed and the European Environmental Noise Directive was adopted in 2002.

The best and most cost-effective approaches to noise mitigation are those at source, such an approach being also valid for industrial metallurgical activities. In conclusion, a mix of mitigation at source and noise abatement at the receiver end will be important to target noise hotspots in Europe. Although there remains room for improvement in terms of technical capability and cost-efficiency, important progress has been made in developing noise abatement technologies in recent years, which — together with robust legislation — will pave the way to a quieter Europe. 


\section{REFERENCES}

[1] CONSTANTINESCU, D., CARLAN A.B. Elements for the modeling of the thermal process in heating furnaces for steel forming, In: COMAT 2016. Plzen, Czech Republic, 2016.

[2] TANASESCU, F.T., STANCIU, V., NITU, S., NITU, C. Agenda Tehnica. Bucharest: Editura tehnică, 1990, pp. 169-172

[3] EUROPEAN COMMISSION: Science for Environment Policy. [online]. April 2017, Issue 17. Available from: https://doi.org/10.2779/016648. ISBN 978-92-79-67011-4.

[4] LETTRE D'INFORMATION DE BRUIT. Spécial étude. [online]. Septembre 2015, no. 20. ISSN 2263-2239; ISSN 2261-3161. Available from : https://www.bruitparif.fr.

[5] Indicateurs Lden et Ln ; Indicateurs Lden et Ln - Site du bruit.htm. [online]. Available from : http://bruit.seine-etmarne.fr/indicateurs-Iden-et-In. 